Article

\title{
Effect of Ultrasonic Surface Impact on the Fatigue Properties of Ti3Zr2Sn3Mo25Nb
}

\author{
Zhangjianing Cheng ${ }^{1}$, Xiaojian Cao ${ }^{2, *}$, Xiaoli $\mathrm{Xu}^{2}{ }^{2}$, Qiangru Shen ${ }^{2}$, Tianchong $\mathrm{Yu}^{2}$ and \\ Jiang Jin ${ }^{2}$ \\ 1 College of Civil Engineering, Tongji University, Shanghai 200092, China; 1911382@tongji.edu.cn \\ 2 School of Transportation \& Civil engineering, Nantong University, Nantong 226019, China; \\ xuxiaoli@ntu.edu.cn (X.X.); shenqr@ntu.edu.cn (Q.S.); yu_tianchong@163.com (T.Y.); jin.j@ntu.edu.cn (J.J.) \\ * Correspondence: cxj1983@ntu.edu.cn
}

Received: 23 March 2020; Accepted: 29 April 2020; Published: 2 May 2020

\begin{abstract}
The effect of nano grain surface layer generated by ultrasonic impact on the fatigue behaviors of a titanium alloy Ti3Zr2Sn3Mo25 Nb (TLM) was investigated. Three vibration strike-numbers of 24,000 times, 36,000 times and 48,000 times per unit are chosen to treat the surface of TLM specimens. Nanocrystals with an average size of $30 \mathrm{~nm}$ are generated. The dislocation motion plays an important role in the transformation of nanograins. Ultrasonic surface impact improves the mechanical properties of TLM, such as hardness, surface residual stress, tensile strength and fatigue strength. More vibration strike numbers will cause a higher enhancement. With a vibration strike number of 48,000 times per square millimeter the rotating-bending fatigue strength of TLM at $10^{7}$ cycles is improved by $23.7 \%$. All the fatigue cracks initiate from the surface of untreated specimens, while inner cracks appear after the fatigue life of $10^{6}$ cycles with the ultrasonic surface impact. The crystal slip in the crack initiation zone is the main way of growth for microcracks. Crack cores are usually formed at the junction of crystals. The stress intensity factor of TLM titanium alloy is approximately $7.0 \mathrm{MPa} \cdot \mathrm{m}^{1 / 2}$.
\end{abstract}

Keywords: fatigue; surface modification; titanium alloy; nanocrystal

\section{Introduction}

As a kind of advanced multifunctional material, biomedical materials can be used to diagnose, cure, repair or replace human tissues, organs or enhance their functions. Their unique efficacy is irreplaceable by drugs. In view of the high strength-to-weight ratio and excellent corrosion resistance, titanium and its alloys are widely used in medical instruments and biomedical implants. According to the development history and long-term clinical feedback of medical titanium alloys, its future focus continues to be the in vitro biocompatibilities and mechanical compatibilities. The ultimate aim is to improve its in vivo biological safety and persistent service. Pure Ti and Ti3Al2.5V were chosen to make dental implants, which bear less stress in mouth, in the 1950s [1]. Since the end of the 1970s, a higher strength titanium alloy Ti6Al4V has been extensively applied in the medical field, such as hip joint, cardiac valves and artificial bones [2]. Ti6Al7Nb and Ti5Al2.5Fe were developed in the corresponding period but it was found that the elements aluminum and vanadium are harmful to the human body. In addition, the large difference between these titanium alloys (more than $100 \mathrm{GPa}$ ) and bones (3-40 GPa) causes stress shielding [3]. Because of the stress shielding, clinical images show that the prosthetic loosening, osteonecrosis and bone degeneration usually happen. In recent decades, a kind of titanium alloy with no toxic element, high strength and low elastic modulus has been the main subject for researchers. Till now, nearly 20 new titanium alloys have been successfully developed. They are called new $\beta$-type titanium alloys. The reason is that the elements molybdenum, 
thallium, niobium and so on, are stable elements of $\beta$-phase. The tensile properties are listed in Table 1. Ti3Zr2Sn3Mo25 Nb (TLM) is one of these materials, and it has a low elastic modulus of approximately $45 \mathrm{GPa}$. So it is anticipated that TLM will play a role in the future.

Table 1. Mechanical properties of some titanium alloys for biomedical use.

\begin{tabular}{cccccc}
\hline Material & $\boldsymbol{\sigma}_{\mathbf{0 . 2}} \mathbf{( M P a )}$ & $\boldsymbol{\sigma}_{\mathbf{b}} \mathbf{( M P a )}$ & $\delta \mathbf{~ ( \% )}$ & $\mathbf{\Psi}(\mathbf{\%})$ & Elastic Modulus (GPa) \\
\hline Pure Ti [4] & $170-485$ & $240-550$ & $15-24$ & $25-30$ & $\approx 103$ \\
Ti6Al4V(annealed) [5] & $820-870$ & $900-930$ & $6-10$ & $20-25$ & $110-114$ \\
Ti6Al7Nb [6] & $880-950$ & $900-1050$ & $8-15$ & $25-45$ & 114 \\
Ti13Nb13Zr(aged) [7] & $830-910$ & $970-1040$ & $10-16$ & $27-53$ & $79-84$ \\
Ti15Mo(annealed) [8] & 511 & 874 & 21 & 82 & 78 \\
Ti12Mo6Zr2Fe(annealed) [9] & $1000-1060$ & $1060-1100$ & $18-22$ & $64-73$ & $74-85$ \\
TLM(aged) & $610-950$ & $685-1050$ & $17-23$ & $70-71$ & $45-81$ \\
Ti24Nb4Zr7.9Sn(aged) [10] & $800-1100$ & $850-1150$ & 15 & - & $42-82$ \\
\hline
\end{tabular}

Titanium and its alloys have been qualified in many fields, including space engineering, ocean engineering and biomedical engineering. However, high friction coefficient, poor wear resistance and low hardness limit its application [11]. For many aerospace components, shot peening is a standard finishing process, because of the compressive residual stress and strain-hardening induced by this treatment [12]. The rising of surface distortion and roughness is detrimental to the durability. To improve the fatigue strength of titanium alloys, other surface modification methods are tried by means of self nanocrystallization.

Surface self nanocrystallization (SSN) by mechanical process transforms the surface coarse grains of a bulk material into nano-sized grains by severe plastic deformation (SPD). These mechanical processes include surface mechanical attrition treatment (SMAT) [13], ultrasonic shot peening [14], laser shock peening [15], ultrasonic surface rolling processing [16], ultrasonic nanocrystal surface modification (UNSM) [17] and ultrasonic cold forging technology [18] In summary, the high energy of ultrasonic, laser and squeezing causes severe plastic deformation. It is reported that the mechanical properties can be improved by these methods [12-18].

In general, fatigue cracks usually initiate from the surface and subsurface. Most failures are sensitive to the micro-structures and the topography of the surface. So that, optimizing the surface of metals might enhance their overall performance. The grain refinement mechanisms of metals have been widely studied by researchers, including copper, steel, aluminum alloy, titanium alloy and so on. The reason nanostructured surface layers are generated from coarse-grains involves the dislocations, twinning and the development of grain boundaries with high angle misorientation [19]. It is accepted that the lattice structure and the stacking fault energy (SFE) decides the plastic deformation behavior and the dislocation in metals and alloys.

In the present work, a nanostructured surface layer was achieved by means of ultrasonic impact on TLM titanium alloy, which was processed with three different numbers of impacts per $\mathrm{mm}^{2}$. The micro-hardness, residual stress, grain size and crystal orientation were measured. The effect of ultrasonic impact on the rotating-bending fatigue behavior of TLM was also investigated. The stress intensity factor based on fish-eye model is calculated to analyze the mechanism of its fatigue characteristic.

\section{Experimental Procedures}

The test specimen in this investigation was a $\beta$-phase titanium alloy TLM titanium alloy shaft with the following chemical composition (mass \%): Mo-3.1, Zr-3.07, Sn-2.09, Nb-24.8, C-0.015, O-0.16, $\mathrm{N}-<0.008, \mathrm{H}-0.003$ and balance Ti. All the specimens were treated with solid solution-aging $\left(750^{\circ} \mathrm{C} / 30\right.$ $\mathrm{m}+510^{\circ} \mathrm{C} / 4 \mathrm{~h}+$ furnace cooling). The mechanical properties of TLM are listed in Table 2 . The tensile test was operated by a universal mechanical tester (CRIMS-DNS400, China Sinotest Sci. \& Tech. Co. Ltd., Nantong, China). 
Table 2. The mechanical properties of TLM titanium alloy.

\begin{tabular}{ccccc}
\hline Heat Treatment & $\boldsymbol{\sigma}_{\mathbf{0 . 2}} / \mathbf{M P a}$ & $\boldsymbol{\sigma}_{\mathrm{b}} / \mathbf{M P a}$ & Elongation/\% & Reduction of Area/\% \\
\hline Solution and aging & 567 & 721 & 19.5 & 71 \\
\hline
\end{tabular}

The principle of the ultrasonic impact process uses ultrasonic vibratory energy at a frequency of $30 \mathrm{kHz}$, and tens of thousands of strikes per $\mathrm{mm}^{2}$ are applied to the material surface as constant pressure [20]. These strikes generate severe plastic deformation on the surface and induce a crystal refined surface layer till nano-sized. Compared with UNSM which is introduced by Pyun [21], the main difference is that the surface is processed without static load here. The ball tip has a diameter of $8.00 \mathrm{~mm}$ which is bigger than the one used in UNSM. It is made of cobalt with a tungsten carbide coating. The vibration amplitude was $30 \mu \mathrm{m}$. The numbers of vibration strike are 24,000 times $/ \mathrm{mm}^{2}$, 36,000 times $/ \mathrm{mm}^{2}$ and 48,000 times $/ \mathrm{mm}^{2}$, respectively. Four groups of specimens, referred to as untreated, UI-24000, UI-36000 and UI-48000, were prepared.

Cross-sectional observations of the core area was performed with a scanning electron microscope (S-3400N, Hitachi, Nantong, China). After polishing, the specimens were finally etched in Kroll's reagent $\left(\mathrm{HNO}_{3}: \mathrm{HF}: \mathrm{H}_{2} \mathrm{O}=3: 6: 90\right.$, vol\%). Transmission electron microscopy (TEM) investigations were carried out with a FEI Tecnai G2 F20 S-TWIN. The specimen for TEM was prepared by focused ion beam (FEI Helios Nanolab 600i), to a depth of $0.5 \mu \mathrm{m}$. The orientation, length and density were characterized by electron backscatter diffraction (EBSD, Leica EM RES 102). The surface of the specimen was fine polished with argon ion.

The microhardness was measured with a Vickers hardness tester (CMM-20E, Changfang, Chengdu, China) with a load of $50 \mathrm{~g}$ and duration of $20 \mathrm{~s}$. The hardness test was performed along three lines. $\mathrm{X}$-ray diffraction (XRD) was used to measure the residual stress using Rigaku X'pert pro MPD. The $\mathrm{Cu}$ $\mathrm{K} \alpha$ radiation $(\lambda=1.54184 \AA)$ was used, and the diffraction lattice plane (213) was examined within a range $2 \theta$ of $113^{\circ}$ to $116^{\circ}$.

To investigate the effect of the nanostructured surface layer on the fatigue behavior of TLM, rotating-bending fatigue test on the four groups of samples (untreated, UI-24000, UI-36000 and UI-48000) were conducted at ambient temperature using an Ono fatigue test machine (Shimadzu, Fukuoka, Japan). The load is applied as four point bending. The frequency was $50 \mathrm{~Hz}$. The dimensions of the fatigue sample are illustrated in Figure 1. The fracture surfaces were examined using a scanning electron microscope (GeminiSEM 300, Zeiss). Energy-dispersive X-ray spectroscopy (EDX) was also used to detect the composition of any inclusions which induced the inner crack initiation with it.

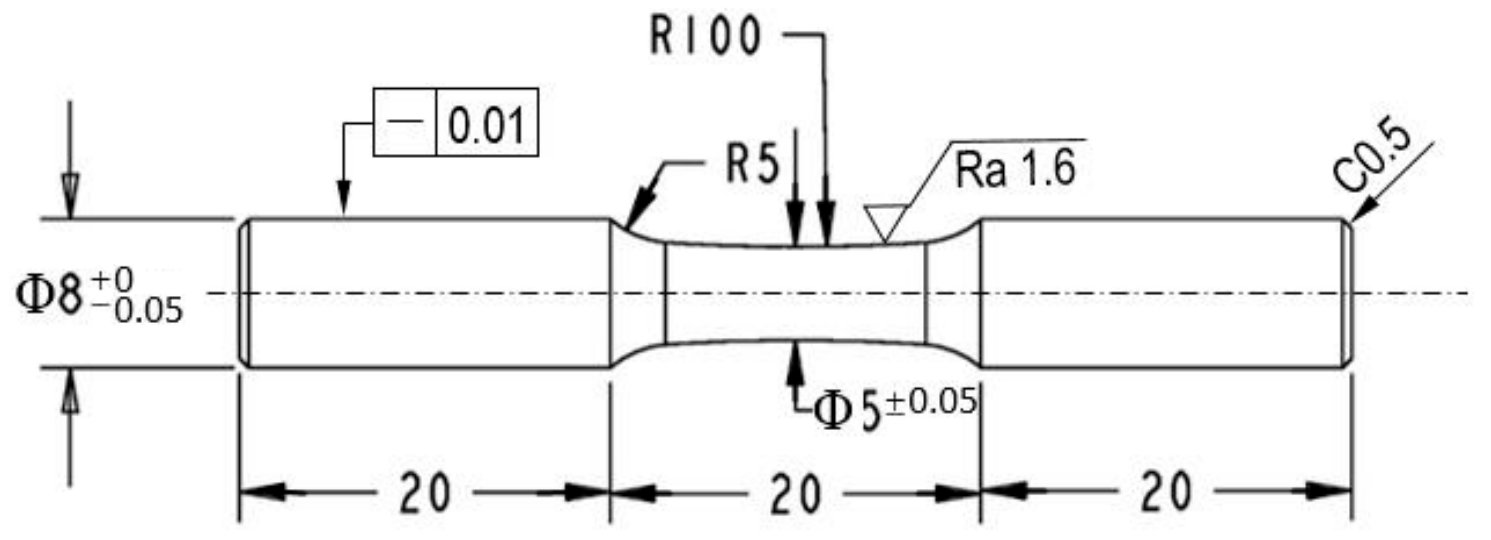

Figure 1. Geometrical dimensions and surface characteristics of the fatigue specimen. 


\section{Results and Discussion}

\subsection{Observation of the Severe Plastic Deformation Layer}

The microstructure characterizations of the SPD layers are usually described by means of TEM. Furthermore, it is generally accepted that nanocrystals can be obtained with the ultrasonic surface strikes [22]. The microstructural changes of the TLM titanium alloy surface are shown in Figure 2. It indicates that high density dislocations and dislocation cells are generated by ultrasonic strikes. Dislocation cells are large and have thin walls composed of tangled dislocations. Continuous slip band are observed on the $\beta$-phase crystal obviously. In Figure 2a, it shows that an amorphous region is formed underneath the surface and the grains are refined to nanometer scales. The average size is about $30 \mathrm{~nm}$. According to Figure 3, the original grain size of the base material is approximately $50 \mu \mathrm{m}$, the microstructures are observed as isometric crystals. It is demonstrated that the parameter combinations without static load are enough to generate nanograins in the surface of the TLM titanium alloy. It is introduced that the dynamic load of ultrasonic strikes is about two times that of static load [23], severe plastic deformation layers are usually shown with rheological trend. However, the legible strain flow was not observed because static load was not introduced here. It is reported that twinning exists in $\alpha$-titanium because of the low hexagonal symmetry [24]. Hexagonal close packed (hcp) $\alpha$-phase has an SFE higher than $300 \mathrm{~mJ} / \mathrm{m}^{2}$, body centered cubic (bcc) $\beta$-phase theoretically has 12 slip directions. Thus, for this $\beta$-type TLM titanium alloy, the mechanism of grain refining in TLM titanium alloy is mainly dislocation motion. Because of the large amount of nanocrystals, the SAED pattern of the SPD layer is nearly concentric annulus instead of an hcp or bcc lattice.

\subsection{EBSD Analysis}

After a scanning from surface to the depth of $30 \mu \mathrm{m}$ with a small step width of $0.035 \mu \mathrm{m}$, it was clear that crystals begin to be continuously distinguished by EBSD up to $20 \mu \mathrm{m}$. This means that the depth of nanocrystal layers are not more than $20 \mu \mathrm{m}$. The misorientation of the boundary is characterized by values of $2^{\circ}$ to $60^{\circ}$. Figure 4 a shows the area examined by EBSD, which is a square with a depth to center of $100 \mu \mathrm{m}$. Figure $4 \mathrm{~b}$ shows the unique grain color map with the inverse pole figure. Each grain is assigned a color to distinguish it from neighboring grains. Because this square starts from the depth of $25 \mu \mathrm{m}$ only a small quantity of grains with the size of less than $10 \mu \mathrm{m}$ are observed. The average size of the grains on the right side, are larger than those on the left. The pink spots indicate that dislocation glide happens in that position. Figure $4 \mathrm{c}$ shows the inverse pole figure analysis and the change in color in each grain corresponds to that in crystal orientation. For the plasticity induced by tensile testing in the beta-titanium alloy, twinning is observed as the main reason [25]. The primary causes of severe plastic deformation of TLM are the dislocation motion and a little of the lattice rotation. From the orientation information, it can be seen that there is obvious preferred orientation in the grains. The $\mathrm{c}$ axis of grain is mainly in $\mathrm{Y}$ direction. 

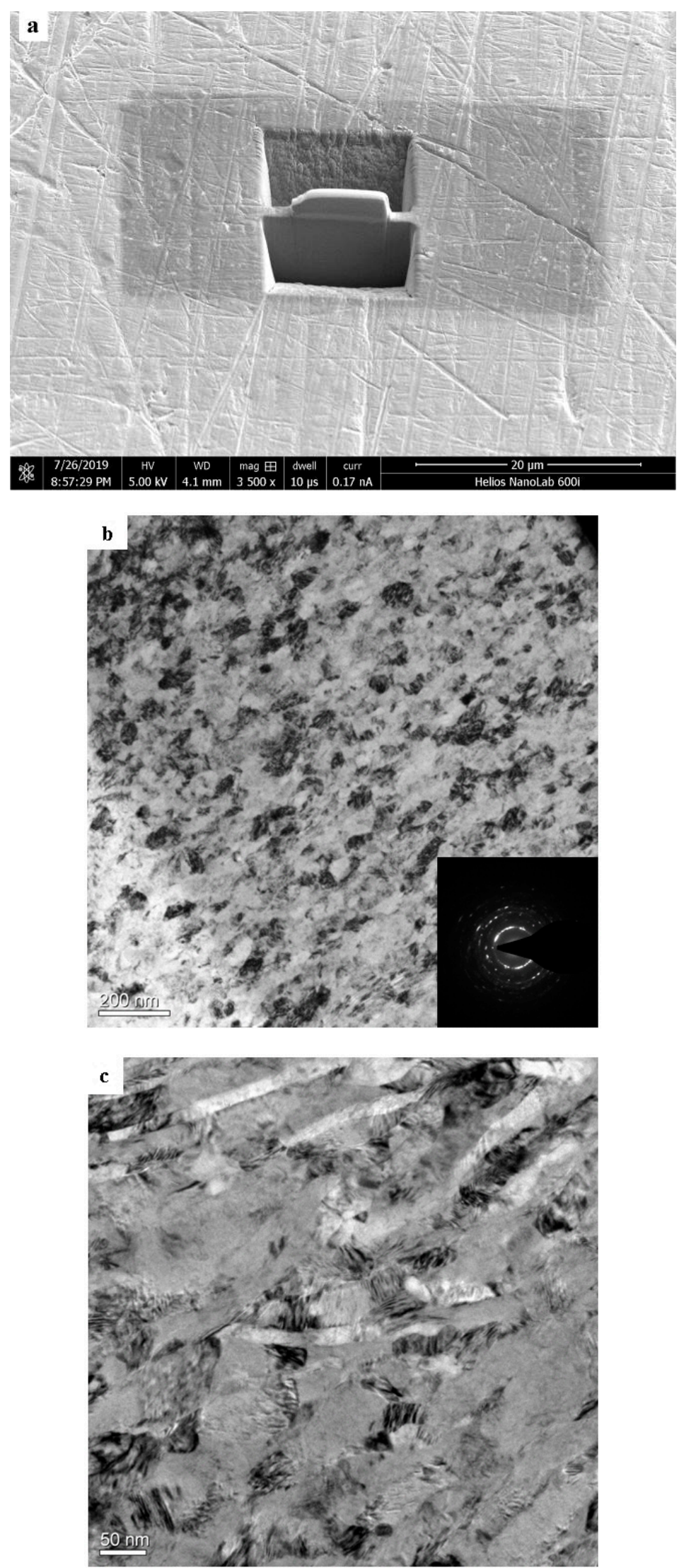

Figure 2. TEM observation of TLM with ultrasonic surface impact: (a) TEM sample prepared by FIB; (b) image and diffraction pattern; (c) dislocation walls. 

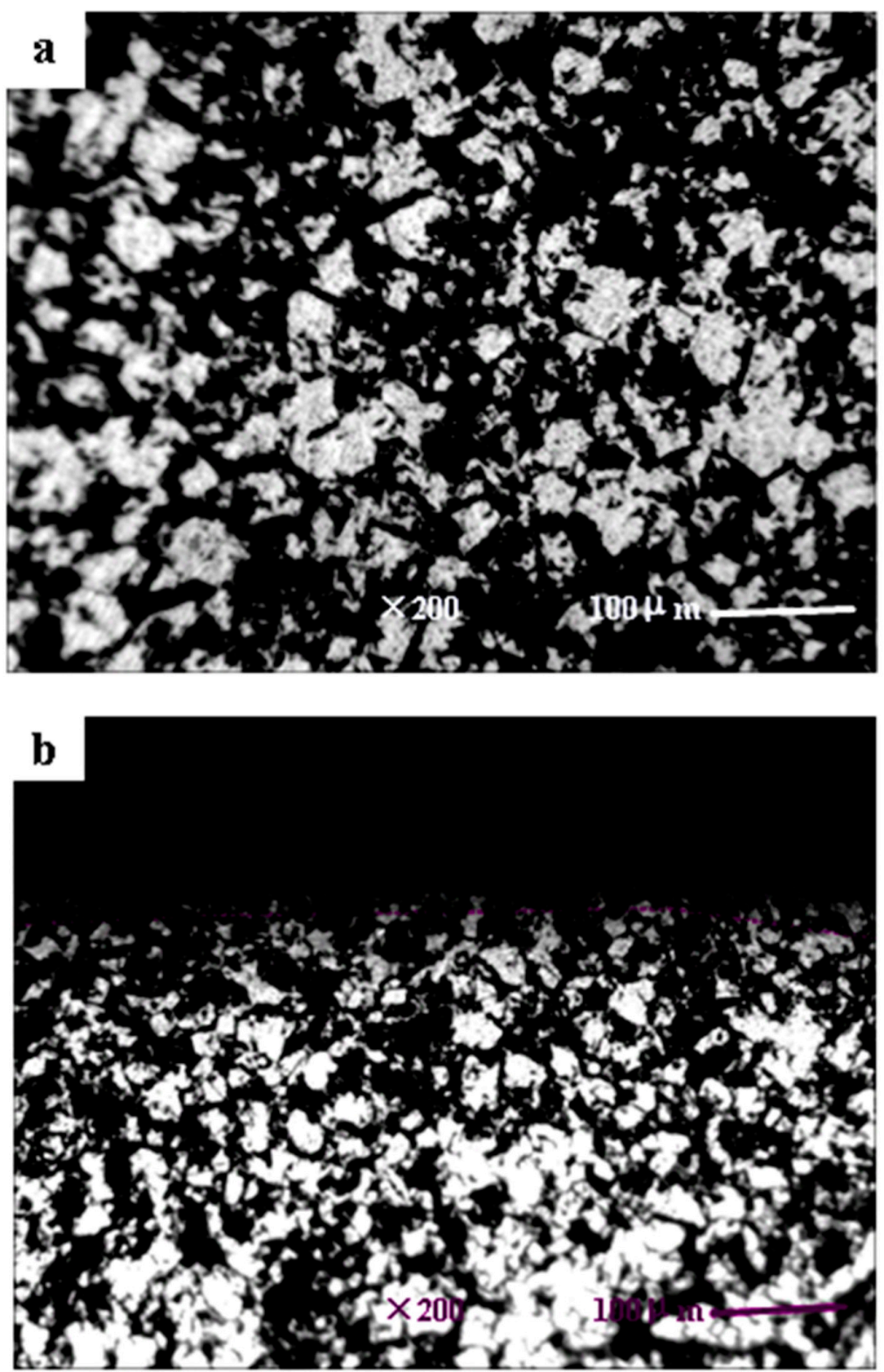

Figure 3. Optical micrograph of TLM titanium alloy: (a) Base material; (b) UI-48000.

\subsection{Micro Vickers Hardness Distrubution}

The average hardness along the depth from the surface to $400 \mu \mathrm{m}$ is depicted in Figure 5 . Where, the hardness was measured perpendicular to the cross-sectional while it was tested vertical to the surface. It is about $238 \mathrm{HV}$ of the untreated TLM base material. The micro-hardness of UI-24000, UI-36000 and UI-48000 is $288 \mathrm{HV}$ (about 21\% improvement), $294 \mathrm{HV}$ and $291 \mathrm{HV}$, respectively. The hardness after surface impact rapidly decreases to $200 \mu \mathrm{m}$ and then decreases gradually to the core. It is well known that the hardness and the yield stress relate to the grain size according to the Hall-Petch theory. It is reported that the subgrain size will not change while the dislocation multiplication rate is balanced $[19,26]$. At this time, the maximum surface hardness will not increase any more. In this paper, each point is subjected to the ultrasonic impacts for two seconds without static load. The surface hardness would be anticipated to be more if the strike number per unit was bigger and the static pressure was adopted. 

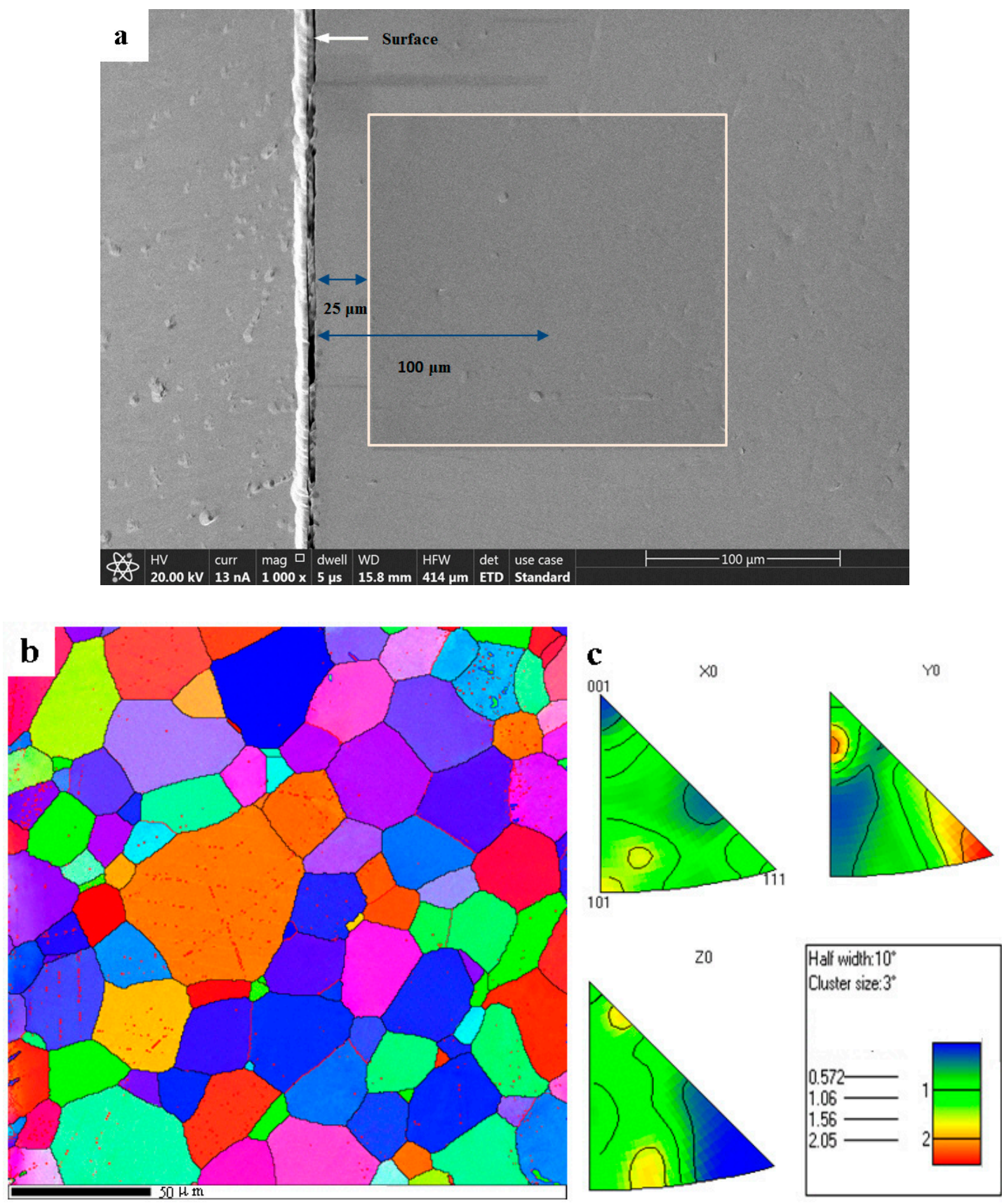

Figure 4. EBSD analysis results: (a) Scanning zone; (b) grain boundary map; (c) inverse pole figure.

\subsection{Residual Stress}

It is well known that high compressive residual stress can be induced by means of ultrasonic impact $[27,28]$. The surface residual stress of untreated specimens is a tensile stress of $12.05 \mathrm{MPa}$. For the TLM specimens subjected to ultrasonic surface impact, the residual stresses below the depth of $20 \mu \mathrm{m}$ were measured. Table 3 lists the residual stress measurement results. It is observed that compressive residual stress is induced at the surface of the TLM specimens. As the strike number per unit increases, the value increases synchronously. The compressive residual stress of UI-24000, UI-36000 and UI-48000 are 247.84 MPa, 273.60 MPa and 288.52 MPa, respectively. The stress values here are less than that of materials treated by UNSM with static load, such as SCM 435 [29]. Compressive residual stress is an important factor for increasing the fatigue resistance. It effects the position and the shape of inner crack initiation. It is reported that the high compressive residual stress of TC4 which is 
treated by UNSM rapidly decreases from the depth of $50 \mu \mathrm{m}$ to $200 \mu \mathrm{m}$ [5]. Thus, cracks are initiated easily in this zone without the nanograins and the compressive residual stress.

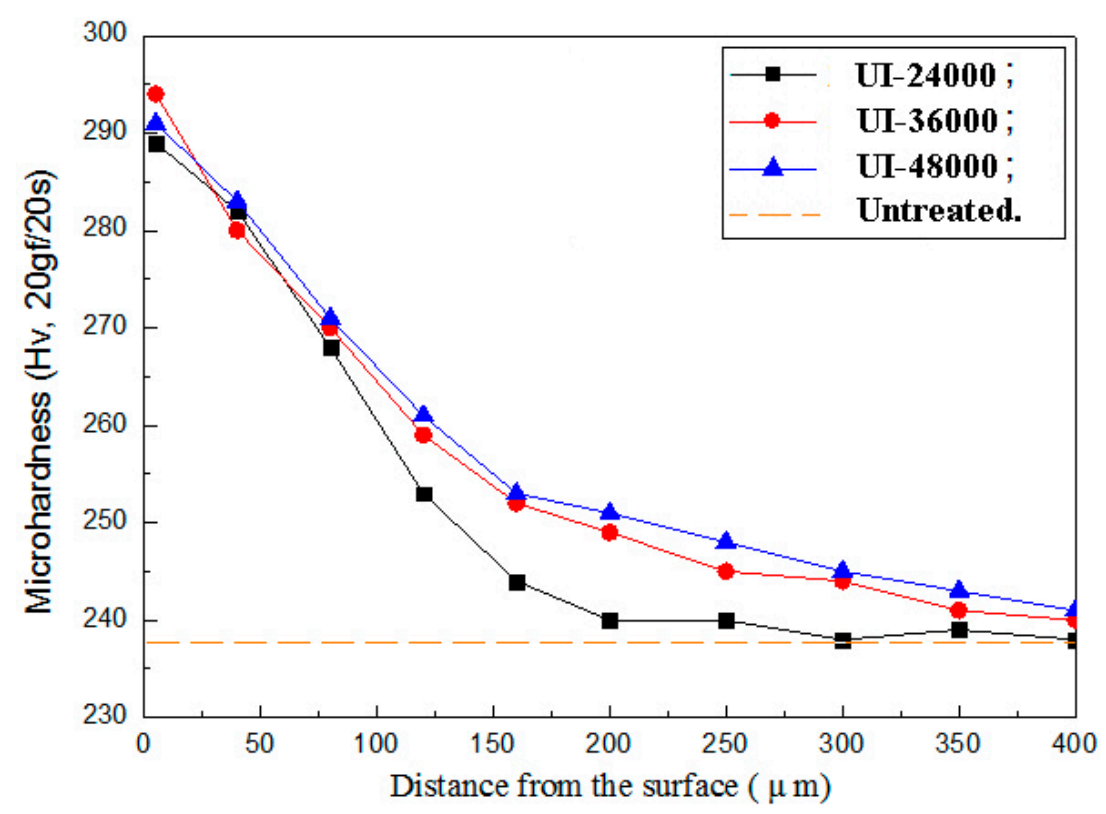

Figure 5. Distribution of surface hardness with ultrasonic surface impact.

Table 3. Residual stress of TLM titanium alloy.

\begin{tabular}{ccccc}
\hline Processing Method & Untreated & UI-24000 & UI-36000 & UI-48000 \\
\hline Residual stress $(\mathrm{MPa})$ & +12.05 & -247.84 & -273.60 & -288.52 \\
\hline
\end{tabular}

\subsection{Tensile Properties}

Figure 6 shows a tensile stress-strain curve for TLM titanium alloy before and after ultrasonic surface impact treatment. Because the differentiation of four tensile curves is tiny, only the curves of untreated and UI- 48000 are given. The sample of UI-48000 has a nanostructured surface layer. As mentioned above, the thickness of this layer is less than $20 \mu \mathrm{m}$. Both the samples have the same geometry. The yield strength increases by $3.17 \%$, while the ultimate tensile stress is increased by about $2.36 \%$ (from $721 \mathrm{MPa}$ to $738 \mathrm{MPa}$ ). It is reported that the tensile stress of $316 \mathrm{~L}$ stainless steel is increased by about $13 \%$, while the yield strength increases from $280 \mathrm{MPa}$ to $550 \mathrm{MPa}$ after SMAT. The reason is the phase transformation of martensite [23].

Elastic modulus $E$ is a parameter which concerns the cohesion of atoms. It is defined as the slope of its stress-strain curve in the elastic deformation region. Elastic modulus of nanocrystalline $\mathrm{Fe}, \mathrm{Cu}$, $\mathrm{Ni}$ and $\mathrm{Cu}-\mathrm{Ni}$ alloys are lower because of a relatively large volume of pores [30]. From the partial enlarged detail, it can be seen that the elastic modulus of TLM titanium alloy has a minor decrease. Even though the base material gives the most contribution of tensile property, the changes of the mechanical parameters are certainly linked to the grain refinement.

\subsection{Fatigue Characteristics}

The fatigue characteristics of the TLM titanium alloy subjected to ultrasonic surface impact are shown in Figure 7. Specimens that did not encounter failure are shown as run-outs. Inner cracks are marked with vertical bars. After the ultrasonic surface impact process, most cracks transform into inner cracks while the fatigue lives are longer than $10^{6}$ cycles. Contrastingly, cracks initiate at the surface to all the un-treated specimens. From the S-N curves, it is evident that ultrasonic strikes improve the $10^{7}$ cycles fatigue strength of TLM. The fatigue strength of UI-24000, UI-36000 and UI-48000 are increased 
by $13.1 \%, 15.8 \%$ and $23.7 \%$, respectively. Table 4 lists the enhancement of the strength and fatigue limit by ultrasonic surface impact. After surface strengthening by ultrasonic impact, the fatigue performance of bending fatigue specimens was improved and the $10^{7}$ cycles fatigue strength of treated specimens was within 0.50 to $0.65 \sigma_{\mathrm{b}}$. The fatigue data of TLM confirms this data. For some austenite stainless steels with the phase transformation of martensite, the fatigue strength will be further improved [31].

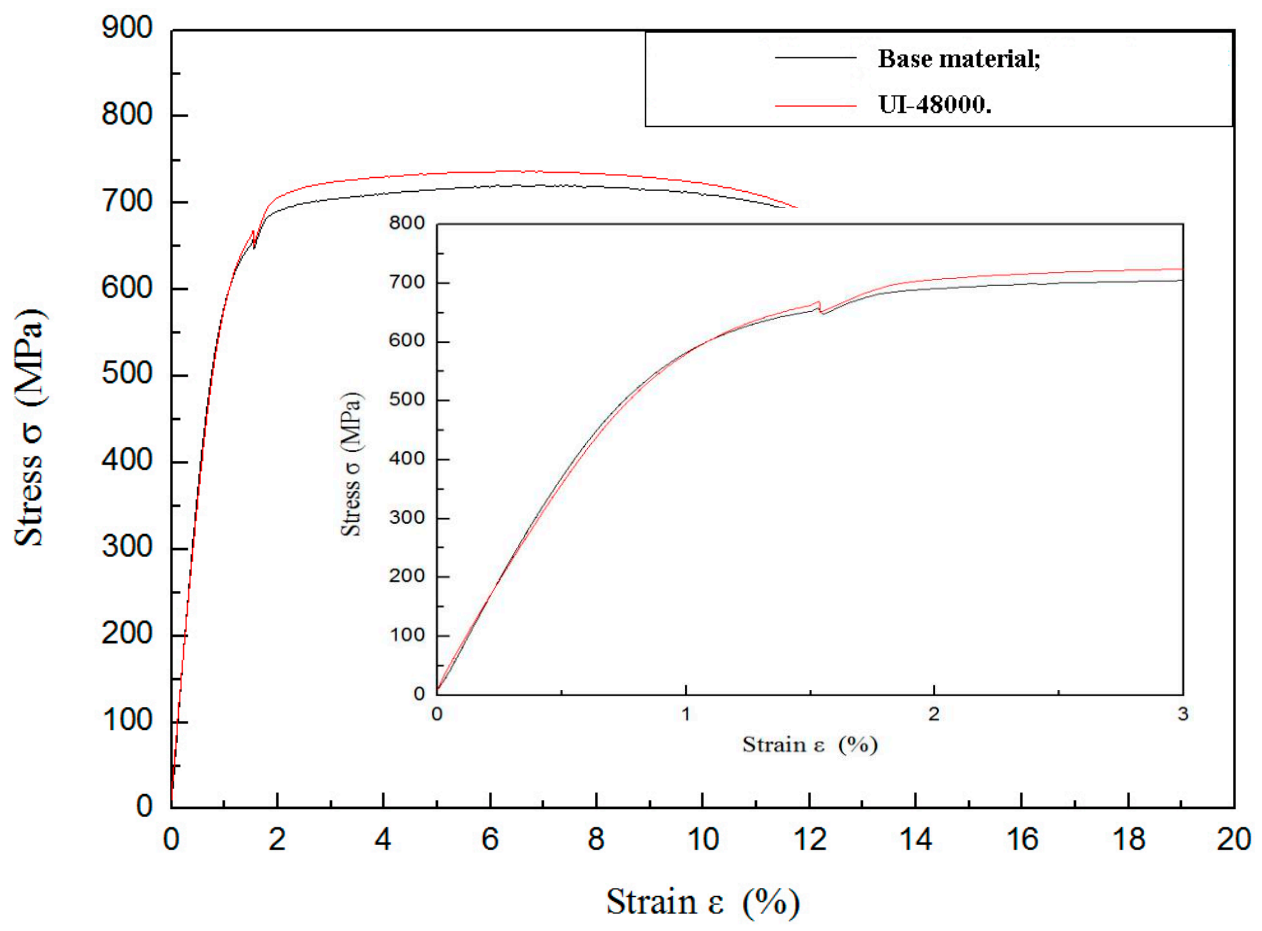

Figure 6. Tensile stress-strain test for TLM titanium alloy.

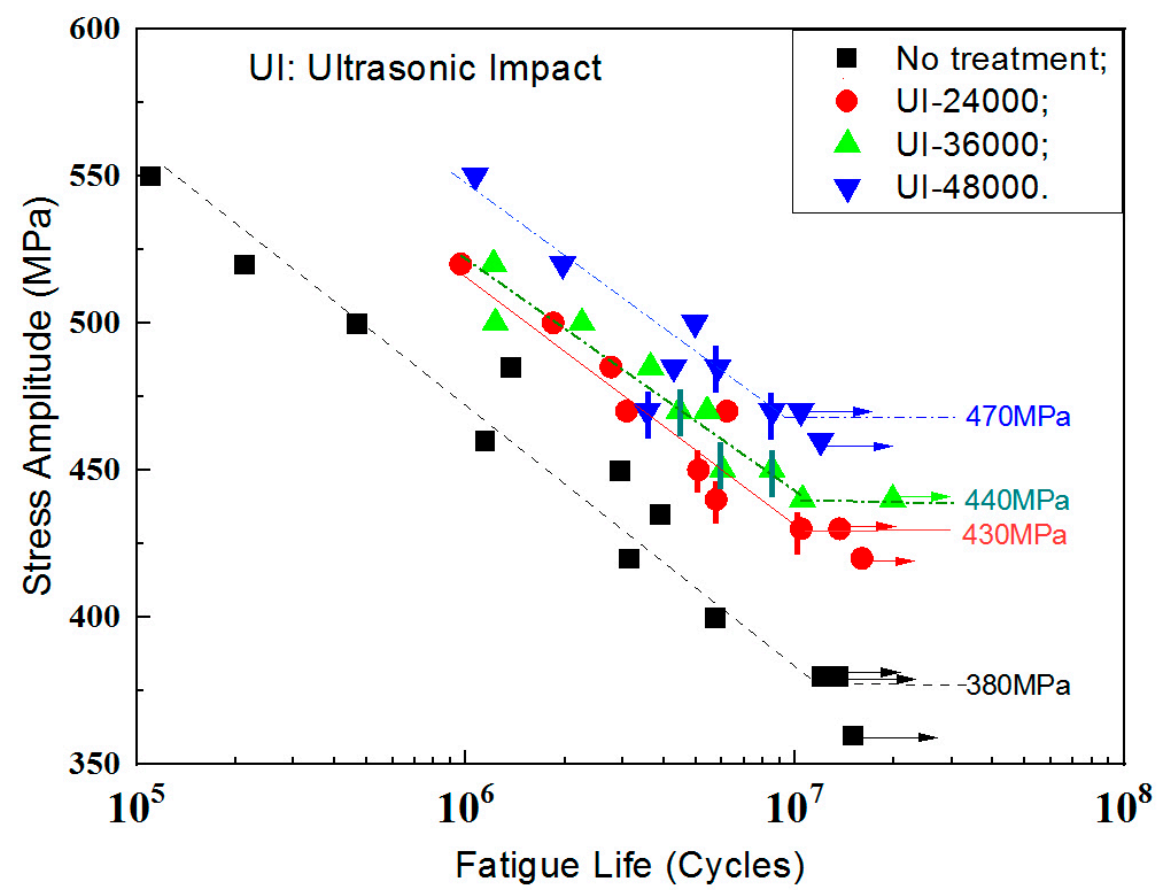

Figure 7. Fatigue S-N curves of TLM titanium alloy. 
Table 4. Enhancement of rotating-bending fatigue limit by ultrasonic surface impact.

\begin{tabular}{|c|c|c|c|c|c|}
\hline \multirow{2}{*}{ Material } & \multirow{2}{*}{ Heat Treatment } & \multirow{2}{*}{$\begin{array}{l}\text { Yield Strength } \\
\sigma_{0.2}(\mathrm{MPa})\end{array}$} & \multirow{2}{*}{$\begin{array}{c}\text { Tensile Strength } \sigma_{\mathrm{b}} \\
\text { (MPa) }\end{array}$} & \multicolumn{2}{|c|}{ Fatigue Limit at $10^{7}$ Cycles (MPa) } \\
\hline & & & & Before & After \\
\hline S45C [32] & Annealed & 490 & 690 & 300 & 400 \\
\hline SUS304 [31] & Hot rolling & 205 & 520 & 280 & 520 \\
\hline SCM435 [29] & $770^{\circ} \mathrm{C} \times 3 \mathrm{~h}+680^{\circ} \mathrm{C} \times 10 \mathrm{~h}$ & 836 & 991 & 500 & 650 \\
\hline ATI 718 plus alloy [27] & $788^{\circ} \mathrm{C} \times 8 \mathrm{~h}+704^{\circ} \mathrm{C} \times 8 \mathrm{~h}$ & 1200 & - & 740 & 850 \\
\hline Inconel 718 alloy [33] & Annealed $954^{\circ} \mathrm{C} \times 30 \mathrm{~m}$ & 829 & 1117 & - & $\approx 700$ \\
\hline A6061 [34] & $\mathrm{T} 6$ & 276 & 310 & 130 & 180 \\
\hline
\end{tabular}

Figures 8 and 9 are the SEM micrographs of the fatigue fracture surface of TLM titanium alloy with fatigue lives of more than $10^{6}$ cycles. Some internal cracks are investigated in this test. All the cracks initiate from the surface of S45C specimens after UNSM which are subjected to a rotating-bending fatigue test [32]. Maximum normal stress in bending is on the surface. Comparing the surface topography of UNSM and which is applied here (as reported by Ao [20]), finer strike tip will cause microcracks easier. The surface integrity influences the fracture crack behavior. To surface self nanocrystallized (SSN) specimen, a nano-structured layer is achieved on the surface. Deeper down there is a refined structured layer consisting of submicrometer-sized crystallites separated by either grain boundaries or sub-boundaries [19]. Then a deformed coarse grain layer forms at a certain depth. In the zone of both the refined structured layer and the deformed coarse grain layer, the lattice distortion and the crystal slip have not balanced to the saturated state. Noticeably, the inner crack cores are at this zone [35]. In addition, the compressed residual stress decreases quickly, the hardness is closed to the core and plasticity and tenacity are weakened in this area [5]. Therefore, indented slip traces of crystals are obvious in the crack initiation. The crystal slip is the main way of the growth of microcracks in the crack initiation zone. It is considered that the facet zone has many small facets due to the slips. Crack cores are usually formed at the junction of crystals instead of inclusions. Thus, it is deduced that the triple grain boundary junction shall be the initiation of the inner fatigue crack as illustrated in Figure 10. For the rotating-bending fatigue test, the maximum normal stress is at the surface. The cracks of all the untreated specimens are generated at the surface. Thus, the crack initiation mechanism is transformed with the application of ultrasonic surface impact. Nanograins prevent the initiation of surface crack. Microcracks which are generated by the plastic overflow after ultrasonic surface strike are observed to be surface defects [5]. Because of the surface maximum bending normal stress and the surface micro defects, some specimens have surface crack initiation with a fatigue life of more than $10^{6}$ cycles.

As it is known that fish-eye-cracks are divided into three areas: inclusion area, facet area and flat area. To most iron-based materials, the first area is the non-metallic compound inclusion in the center of a fish-eye. It is the triple grain boundary junction of the crystal slip to TLM instead. The second is the facet area with a rough surface, as marked in Figure 8a. The flat area is seen as a dark gray ellipse located around the facet area. The stress intensity factor, $\Delta K$, relevant to the facet area can be calculated by Equations (1) and (2) [36],

$$
\begin{gathered}
\Delta K=0.5 \sigma_{a t}(\pi \sqrt{\text { area }})^{1 / 2} \\
\sigma_{a t}=(d-2 h) \sigma_{a} / d
\end{gathered}
$$

where $\sigma_{a}$ is the nominal stress amplitude at the surface, $\sigma_{a t}$ is stress amplitude at the inner crack core, $d$ is diameter of specimen, $h$ is depth of the crack initiation and area is the area of each part. For the TLM titanium alloy, the stress intensity factor calculated from the facet area $\Delta K_{\text {facet }}$ is about $7.0 \mathrm{MPa} \cdot \mathrm{m}^{1 / 2}$. The stress intensity factor $\Delta K_{\text {facet }}$ and $\Delta K_{\text {inclusion }}$ have different propagation mechanisms. For titanium alloys, the non-metallic compound inclusion is not often observed. The facet area can be delimited with the micro facets due to the slip of $\alpha$-phase. From the Murakami equation, it is clear that $\Delta K_{\text {facet }}$ is close to the threshold stress intensity factor $\Delta K_{t h}$. Normally, $\Delta K_{t h}$ is the value to divide the initiation and the steady expanding of cracks according to the fatigue crack growth rate curve. The time of crack initiation usually lasts more than $95 \%$ of the whole fatigue life. To materials with inner cracks, Murakami considers that there is a confirmable maximum value of $\Delta K_{\text {facet }}$ by multiple experiments. 
With the size of inner cracks and the stress intensity factor, the fatigue limit can be estimated by the inversion of the above equations.

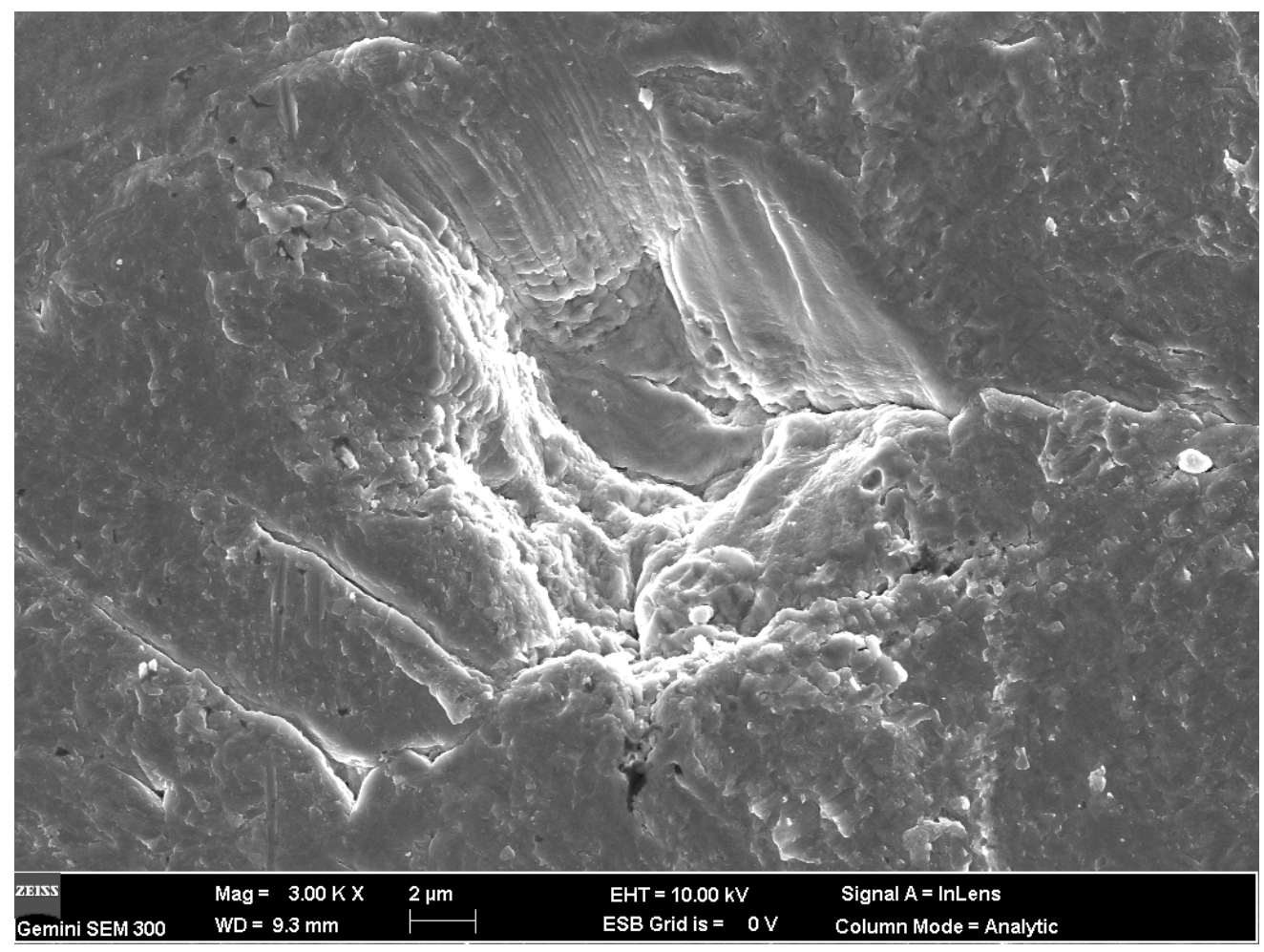

(b)

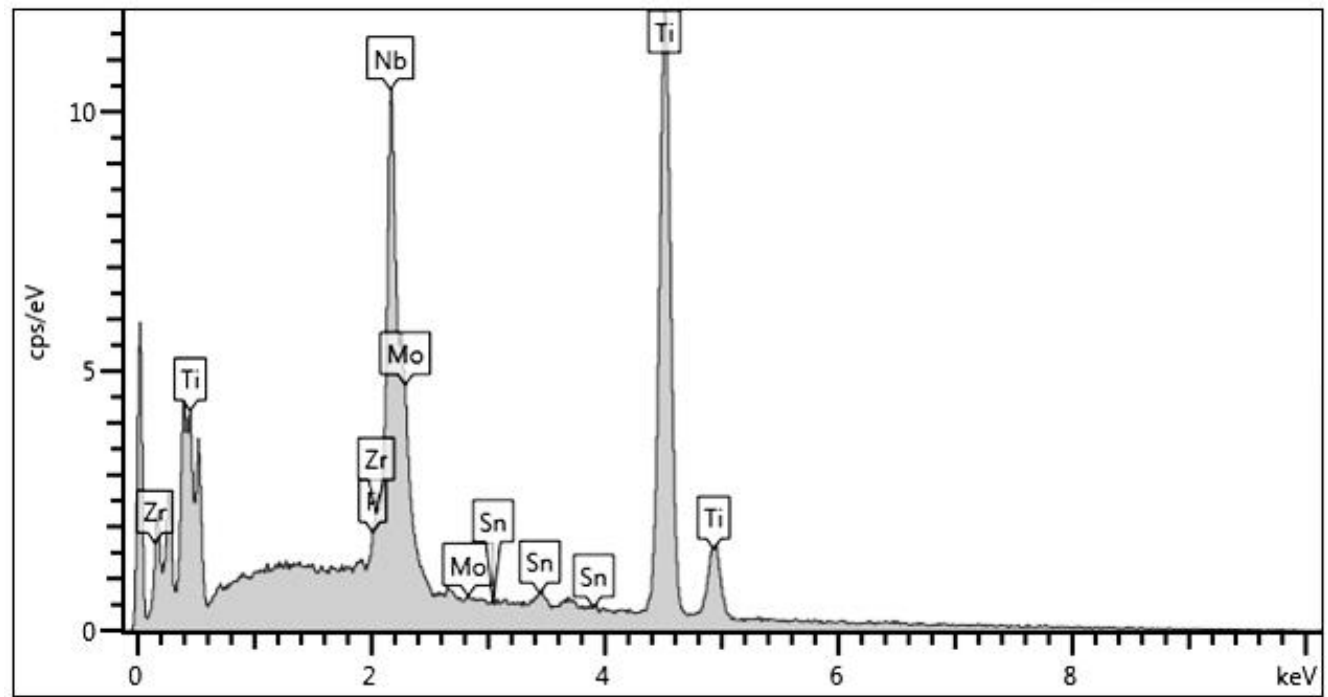

(c)

Figure 8. Cont. 


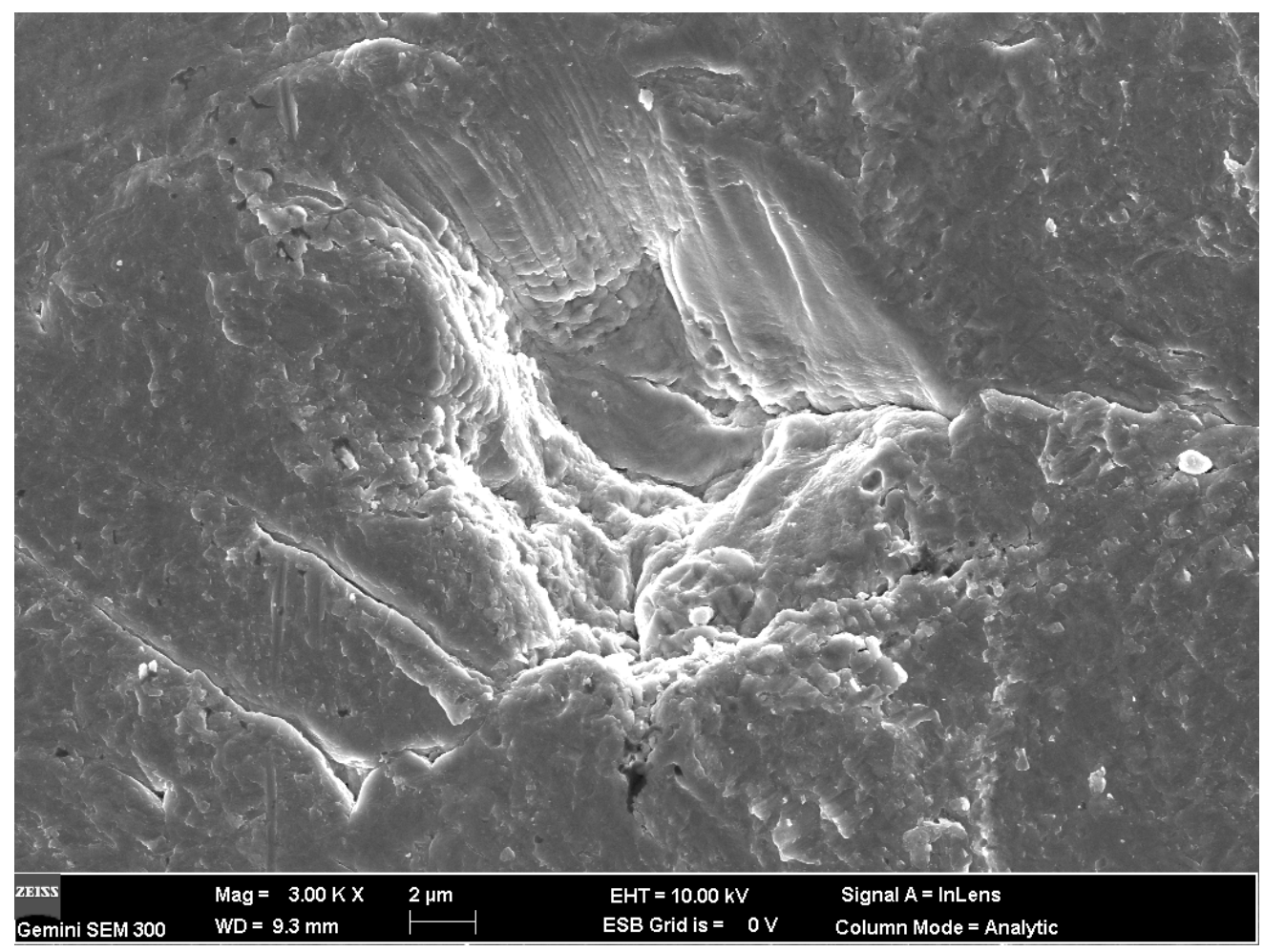

(b)

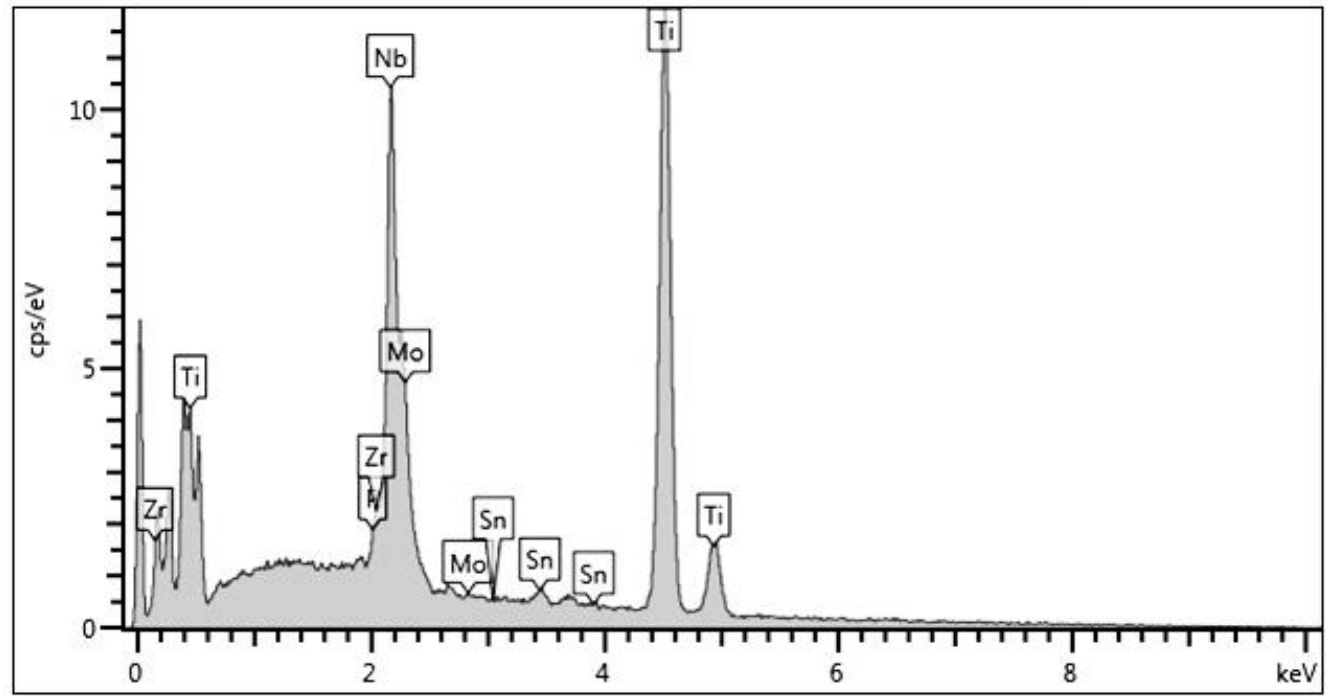

(c)

Figure 8. Fracture surface of TLM (UI-24000, $500 \mathrm{MPa}, 1.86 \times 10^{6}$ cycles): (a) Overall view of fracture surface; (b) slip trace of crystals in the crack initiation; (c) EDX analysis of crack core. 


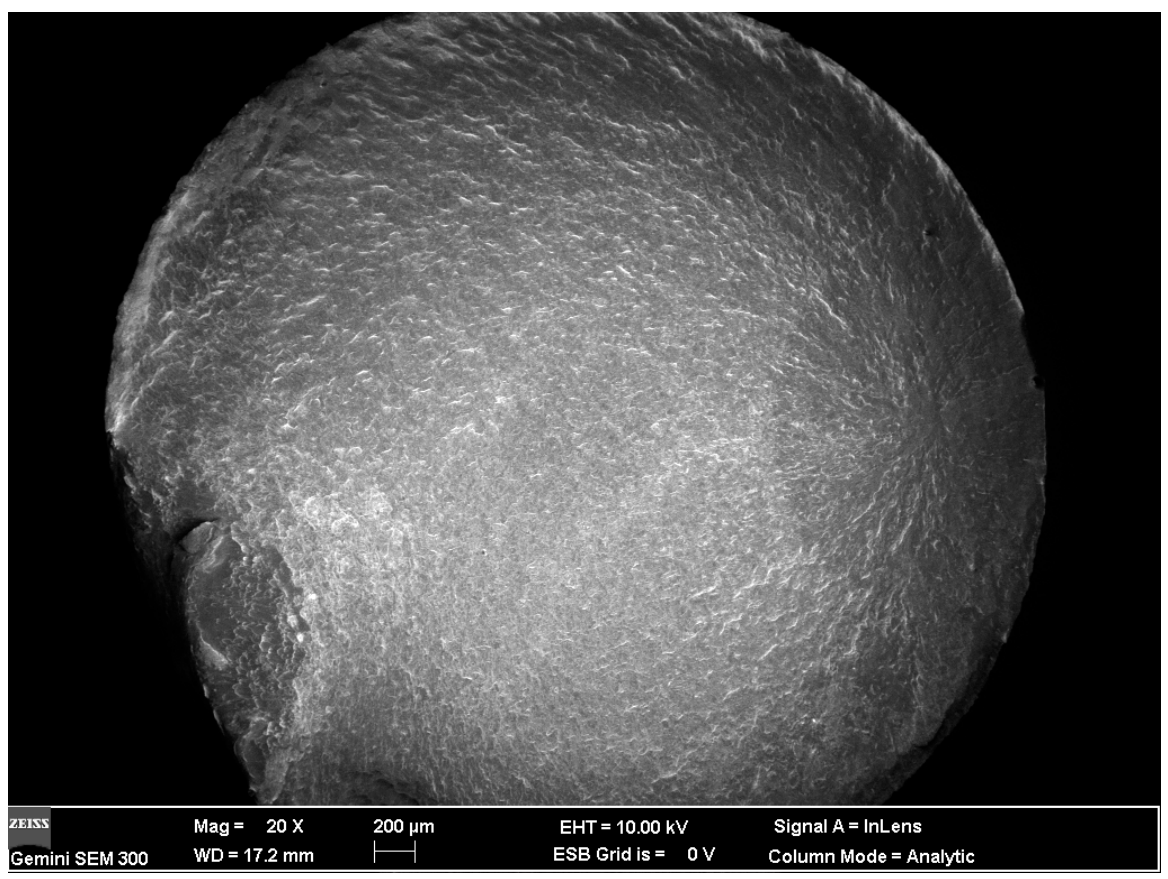

(a)

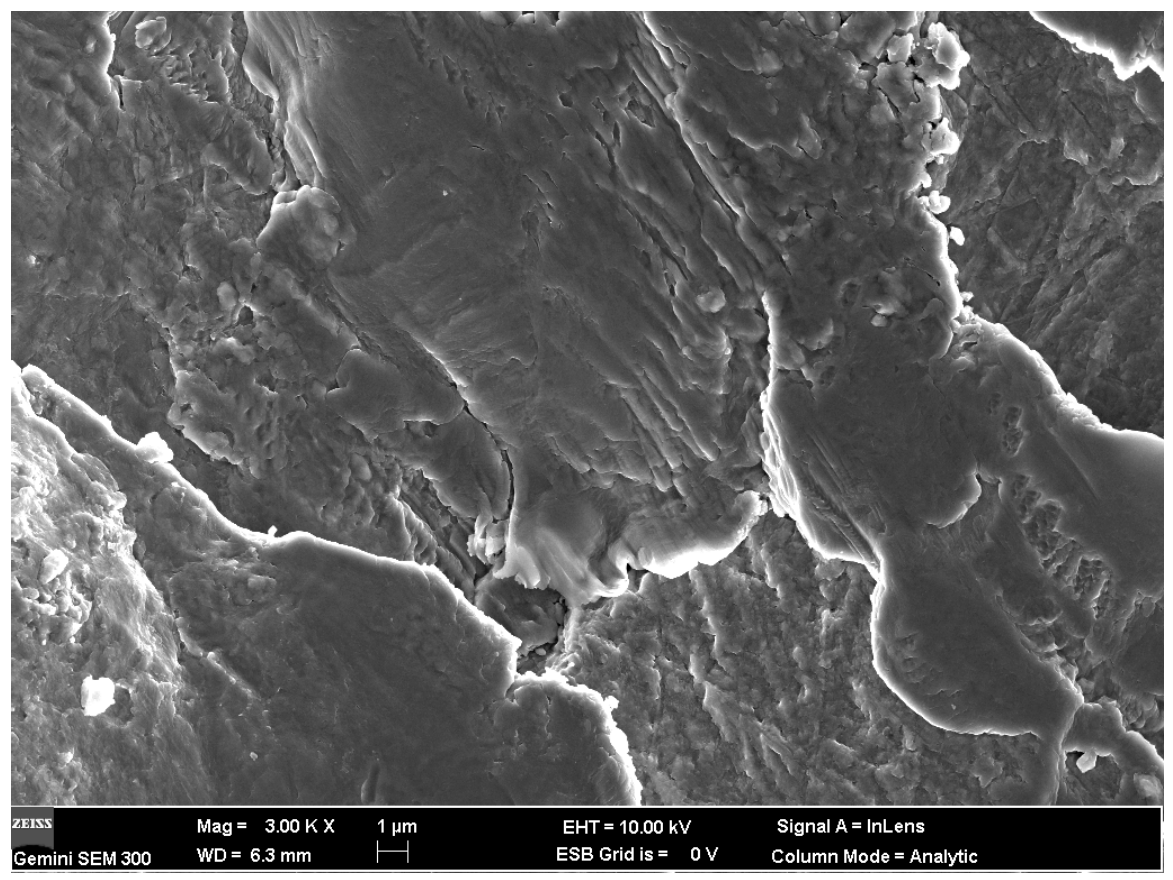

(b)

Figure 9. Fracture surface of TLM (UI-48000, $500 \mathrm{MPa}, 4.97 \times 10^{6}$ cycles): (a) Overall view of fracture surface; (b) slip trace of crystals in the crack initiation. 

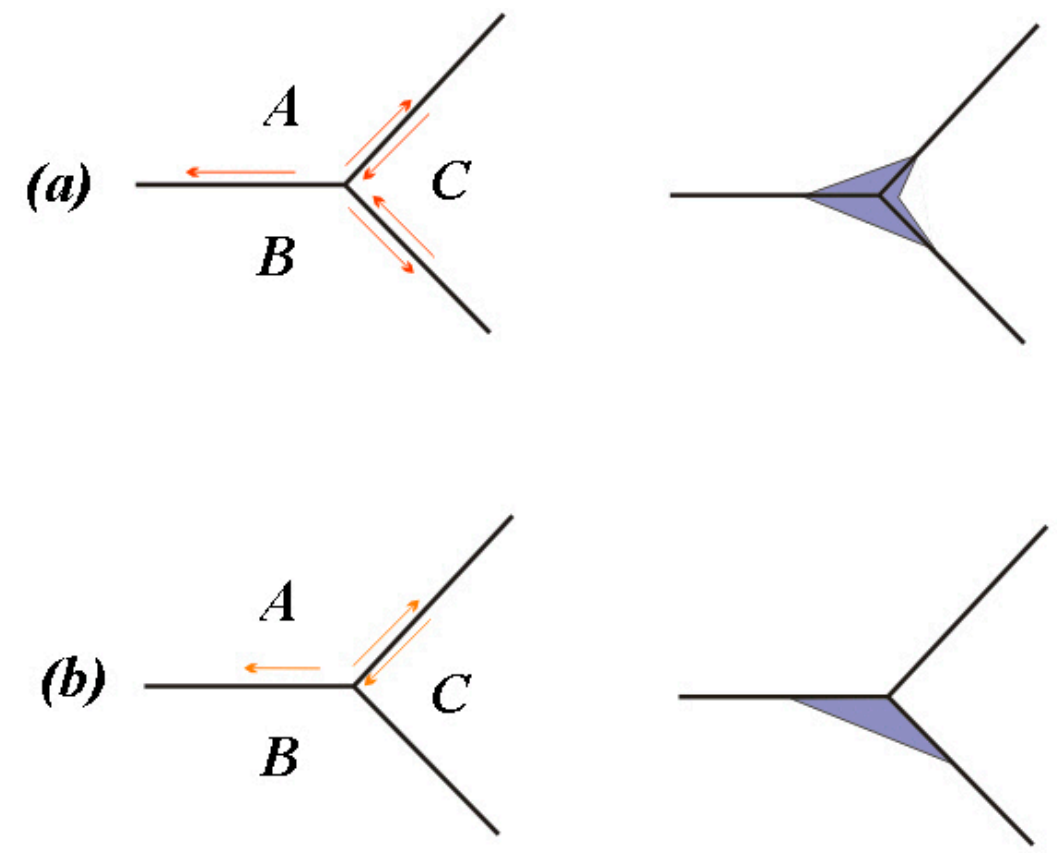

Figure 10. Illustration of the crack at the triple grain boundary junction of the crystal slip: (a) Slips on three grain boundaries; (b) Slips on two grain boundaries.

\section{Conclusions}

Nanocrystals with a size of $30 \mathrm{~nm}$ are generated with the ultrasonic surface impacts. The primary causes of severe plastic deformation of the TLM titanium alloy are the dislocation motion and a little of the lattice rotation. Ultrasonic surface impact improves the micro hardness, the surface compressive residual stress, tensile strength and the fatigue strength of TLM. Specimens which are treated with the higher vibration strike number will have a better enhancement of mechanical properties. With the vibration strike number of 48,000 times per unit, the rotating-bending fatigue strength of TLM at $10^{7}$ cycles is $470 \mathrm{MPa}(23.7 \%$ improvement). Fatigue cracks mainly initiate from the surface of the specimen before the fatigue life of $10^{6}$ cycles, while inner cracks appear at the boundary junction of the crystals after the fatigue life of $10^{6}$ cycles. The stress intensity factor of TLM is approximately $7.0 \mathrm{MPa} \cdot \mathrm{m}^{1 / 2}$.

Author Contributions: Z.C. wrote the paper; X.C. conceived and designed the experiments; X.X. did the grain characterization; Q.S. contributed the surface treatment; T.Y. analyzed the datas; J.J. helped with the model of micro-cracks. All authors have read and agreed to the published version of the manuscript.

Funding: This research received no external funding.

Acknowledgments: The financial support extended by National Natural Science Foundation of China (11802145) is gratefully acknowledged. The research group of Prof. Noguchi Hiroshi at the Kyushu University, experimenter Liu Siyuan in the Analysis and Test Center of Nantong University, and Prof. Song in the Analysis and Test Center of Sichuan University gave us assistance with tests, thank you all very much.

Conflicts of Interest: The authors declare no conflict of interest.

\section{References}

1. Brānemark, P.I.; Adell, R.; Breine, U.; Hansson, B.O.; Lindström, J.; Ohlsson, A. Intra-osseous anchorage of dental prostheses: I. Experimental studies. Scand. J. Plast. Reconstr. Surg. 1969, 3, 81-100. [CrossRef] [PubMed]

2. Yu, Z.T.; Zhang, M.-H.; Tian, Y.-X.; Cheng, J.; Ma, X.-Q.; Liu, H.-Y.; Wang, C. Designation \& development of biomedical Ti alloys with finer biomechanical compatibility in long-term surgical implants. Front. Mater. Sci. 2014, 8, 219-229. 
3. Eylon, D.; Vassel, A.; Combres, Y.; Boyer, R.R.; Bania, P.J.; Schutz, R.W. Issues in the development of beta titanium alloys. JOM 1994, 46, 14-15. [CrossRef]

4. Wang, T.T.; Zeng, L.G.; Li, Z.J. Influences of Laser Surface Alloying with Cr on Microstructural Characteristics and Hardness of Pure Ti. Metall. Mater. Trans. A 2019, 50, 3794-3804. [CrossRef]

5. Cao, X.J.; Xu, L.P.; Xu, X.L.; Wang, Q.Y. Fatigue fracture characteristics of Ti6Al4V subjected to ultrasonic nanocrystal surface modification. Metals 2018, 8, 77. [CrossRef]

6. Hamad, T.I.; Fatalla, A.A.; Waheed, A.S.; Azzawi, Z.G.M.; Cao, Y.-G.; Song, K. Biomechanical Evaluation of Nano-Zirconia Coatings on Ti-6Al-7Nb Implant Screws in Rabbit Tibias. Curr. Med. Sci. 2018, 38, 530-537. [CrossRef] [PubMed]

7. Zhou, L.B.; Yuan, T.C.; Li, R.D.; Tang, J.Z.; Wang, M.B.; Mei, F.S. Anisotropic mechanical behavior of biomedical Ti-13Nb-13Zr alloy manufactured by selective laser melting. J. Alloy. Compd. 2018, 762, 289-300. [CrossRef]

8. Im, Y.D.; Lee, Y.K.; Song, K.H. Effect of Grain Misorientation Angle on Twinning Propagation in Ti-15Mo Alloy. Met. Mater. Int. 2018, 24, 913-917. [CrossRef]

9. Yang, X.Y.; Hutchinson, C.R. Corrosion-wear of $\beta$-Ti alloy TMZF (Ti-12Mo-6Zr-2Fe) in simulated body fluid. Acta Biomater. 2016, 42, 429-439. [CrossRef]

10. Liu, X.H.; Wu, L.; Ai, H.J.; Han, Y.; Hu, Y. Cytocompatibility and early osseointegration of nanoTiO ${ }_{2}$-modified Ti-24 Nb-4 Zr-7.9 Sn surfaces. Mat. Sci. Eng. C 2015, 48, 256-262. [CrossRef]

11. Bloyce, A.; Morton, P.; Bell, T. ASM Handbook; ASM International: Materials Park, OH, USA, 1994; Volume 5.

12. Maawad, E.; Sano, Y.; Wagner, L.; Brokmeier, H.G.; Genzel, C. Investigation of laser shock peening effects on residual stress state and fatigue performance of titanium alloys. Mater. Sci. Eng. A 2012, 536, 82-91. [CrossRef]

13. Benafia, S.; Retraint, D.; Brou, S.Y.; Panicaud, B.; Grosseau Poussard, J.L. Influence of Surface Mechanical Attrition Treatment on the oxidation behaviour of 316L stainless steel. Corros. Sci. 2018, 136, 188-200. [CrossRef]

14. Zhu, L.H.; Guan, Y.J.; Lin, J.; Zhai, J.Q.; Xie, Z.D. A nanocrystalline-amorphous mixed layer obtained by ultrasonic shot peening on pure titanium at room temperature. Ultrason. Sonochem. 2018, 47, 68-74. [CrossRef] [PubMed]

15. Zhang, R.X.; Zhou, X.F.; Gao, H.Y.; Mankoci, S.; Liu, Y.; Sang, X.H.; Qin, H.F.; Hou, X.N.; Ren, Z.C.; Doll, G.L.; et al. The effects of laser shock peening on the mechanical properties and biomedical behavior of AZ31B magnesium alloy. Surf. Coat. Technol. 2018, 339, 48-56. [CrossRef]

16. Ao, N.; Liu, D.X.; Xu, X.; Liu, D. Gradient nanostructure evolution and phase transformation of $\alpha$ phase in Ti-6Al-4V alloy induced by ultrasonic surface rolling process. Surf. Coat. Technol. 2019, 742, 820-834. [CrossRef]

17. Kherandmandfard, M.; Kashani-Bozorg, S.F.; Lee, J.S.; Kim, C.L.; Hanzaki, A.Z.; Pyun, Y.-S.; Pyun, S.-W.; Amanov, A.; Kim, D.-E. Significant improvement in cell adhesion and wear resistance of biomedical $\beta$-type titanium alloy through ultrasonic nanocrystal surface modification. J. Alloy Compd. 2018, 762, 941-949. [CrossRef]

18. She, D.; Yue, W.; Fu, Z.; Gu, Y.; Wang, C.; Liu, J. The effect of nitriding temperature on hardness and microstructure of die steel pre-treated by ultrasonic cold forging technology. Mater. Des. 2013, 49, 392-399. [CrossRef]

19. Lu, K.; Lu, J. Nanostructured surface layer on metallic materials induced by surface mechanical attrition treatment. Mater. Sci. Eng. A 2004, 375, 38-45. [CrossRef]

20. Ao, N.; Liu, D.X.; Zhang, X.H.; Liu, C.G. Enhanced fatigue performance of modified plasma electrolytic oxidation coated Ti-6Al-4V alloy: Effect of residual stress and gradient nanostructure. Appl. Surf. Sci. 2019, 489, 595-607. [CrossRef]

21. Pyun, Y.; Park, J.; Kim, C. Compiler. U.S. Patent 8782902B2, 4 February 2010.

22. Hu, J.; Shi, Y.; Savage, X.; Sha, G.; Lu, K. Grain boundary stability governs hardening and softening in extremely fine nanograined metals. Science 2017, 355, 1292-1296. [CrossRef]

23. Amanov, A.; Karimbaev, R.; Maleki, E.; Unal, O.; Pyun, Y.-S.; Amanov, T. Effect of combined shot peening and ultrasonic nanocrystal surface modification processes on the fatigue performance of AISI 304. Surf. Coat. Technol. 2019, 358, 695-705. [CrossRef] 
24. Zhu, K.Y.; Vassel, A.; Brisset, F.; Lu, K.; Lu, J. Nanostructure formation mechanism of $\alpha$-titanium using SMAT. Acta Mater. 2004, 52, 4101-4110. [CrossRef]

25. Chen, G.Q.; Jiao, Y.; Tian, T.Y.; Zhang, X.-H.; Li, Z.-Q.; Zhou, W.-L. Effect of wet shot peening on Ti-6Al-4V alloy treated by ceramic beads. Trans. Nonferrous Met. Soc. China 2014, 24, 690-696. [CrossRef]

26. Nie, X.F.; He, W.F.; Zhou, L.C.; Li, Q.P.; Wang, X.D. Experiment investigation of laser shock peening on TC6 titanium alloy to improve high cycle fatigue performance. Mater. Sci. Eng. A 2014, 594, 161-167. [CrossRef]

27. Kattoura, M.; Telang, A.; Mannava, S.R.; Qian, D.; Vasudevan, V.K. Effect of ultrasonic nanocrystal surface modification on residual stress, microstructure and fatigue behavior of ATI 718plus alloy. Mater. Sci. Eng. A 2018, 711, 364-377. [CrossRef]

28. Sonntag, R.; Reinders, J.; Gibmeier, J.; Kretzer, J.P. Fatigue performance of medical Ti6Al4V alloy after mechanical surface treatments. PLoS ONE 2015, 10, e0121963. [CrossRef]

29. Suh, C.M.; Yoon, S.M.; Jang, J.H.; Suh, M.S.; Pyoun, Y.S.; Sakai, T. Very high cycle fatigue characteristics of SCM435 under load variation by ultrasonic nanocrystal surface modification treatment. Korean Soc. Mech. Eng. 2009, 11, 66-71.

30. Shen, T.D.; Koch, C.C.; Tsui, T.Y.; Pharr, G.M. On the Elastic Modulus of Nanocrystalline Cu, Ni and Their Alloys Prepared by Mechanical Milling/Alloying. J. Mater. Res. 1995, 10, 2892-2896. [CrossRef]

31. Yasuoka, M.; Wang, P.; Zhang, K.; Qiu, Z.; Kusaka, K.; Pyoun, Y.S.; Murakami, R.I. Improvement of the fatigue strength of SUS304 austenite stainless steel using ultrasonic nanocrystal surface modification. Surf. Coat. Technol. 2013, 218, 93-98. [CrossRef]

32. Cao, X.J.; Murakam, R.; Pyoun, Y.S. Fatigue properties of a S45C steel subjected to ultrasonic nanocrystal surface modification. Appl. Surf. Sci. 2010, 256, 6297-6303. [CrossRef]

33. Amanov, A.; Pyun, Y.; Ssdski, S. Effects of ultrasonic nanocrystalline surface modification (UNSM) technique on the tribological behavior of sintered Cu-based alloy. Tribol. Int. 2014, 72, 187-197. [CrossRef]

34. Lee, C.; Murakami, R.; Suh, C. Fatigue properties of aluminum alloy (A6061-T6) with ultrasonic nano-crystal surface modification. Int. J. Mod. Phys. B 2010, 24, 2512-2517. [CrossRef]

35. Cao, X.J.; Wu, C.J.; Gu, Z.Y.; Chen, Q.; Fukushima, Y.; Liu, Y.J.; Wang, Q.Y. Research status and progress on ultrasonic impact nanocrystallization. Surf. Technol. 2019, 48, 113-121.

36. Murakami, Y. Metal Fatigue: Influence of Micro Defect and Inclusion; Yokenndo: Tokyo, Japan, 1993. (In Japanese) 